\title{
Feeding preferences of Oxpeckers in Kruger National Park, South Africa
}

\begin{tabular}{|c|c|}
\hline \multicolumn{2}{|c|}{$\begin{array}{l}\text { Authors: } \\
\text { Mduduzi Ndlovu'1,2 } \\
\text { Leigh Combrink }^{3}\end{array}$} \\
\hline \multicolumn{2}{|c|}{$\begin{array}{l}\text { Affiliations: } \\
{ }^{1} \text { School of Animal, Plant and } \\
\text { Environmental Sciences, } \\
\text { University of Witwatersrand, } \\
\text { South Africa }\end{array}$} \\
\hline \multicolumn{2}{|c|}{$\begin{array}{l}{ }^{2} \text { Organisation for Tropical } \\
\text { Studies, Skukuza, South } \\
\text { Africa }\end{array}$} \\
\hline \multicolumn{2}{|c|}{$\begin{array}{l}{ }^{3} \text { The Endangered Wildlife } \\
\text { Trust, Gauteng, South Africa }\end{array}$} \\
\hline \multicolumn{2}{|c|}{$\begin{array}{l}\text { Correspondence to: } \\
\text { Mduduzi Ndlovu }\end{array}$} \\
\hline \multicolumn{2}{|c|}{$\begin{array}{l}\text { Email: } \\
\text { mdu.ndlovu@wits.ac.za }\end{array}$} \\
\hline \multicolumn{2}{|c|}{$\begin{array}{l}\text { Postal address: } \\
\text { Private Bag X3, University of } \\
\text { Witwatersrand 2050, South } \\
\text { Africa }\end{array}$} \\
\hline \multicolumn{2}{|c|}{$\begin{array}{l}\text { Dates: } \\
\text { Received: } 22 \text { Apr. } 2015 \\
\text { Accepted: } 30 \text { Aug. } 2015 \\
\text { Published: } 27 \text { Nov. } 2015\end{array}$} \\
\hline \multicolumn{2}{|c|}{$\begin{array}{l}\text { How to cite this article: } \\
\text { Ndlovu, M. \& Combrink, L., } \\
\text { 2015, 'Feeding preferences of } \\
\text { Oxpeckers in Kruger National } \\
\text { Park, South Africa', Koedoe } \\
\text { 57(1), Art. \#1316, } 6 \text { pages. } \\
\text { http://dx.doi.org/10.4102/ } \\
\text { koedoe.v57i1.1316 }\end{array}$} \\
\hline \multicolumn{2}{|c|}{$\begin{array}{l}\text { Copyright: } \\
\text { (C) 2015. The Authors. } \\
\text { Licensee: AOSIS } \\
\text { OpenJournals. This wor } \\
\text { licensed under the Crea } \\
\text { Commons Attribution } \\
\text { License. }\end{array}$} \\
\hline \multicolumn{2}{|l|}{ Read online: } \\
\hline 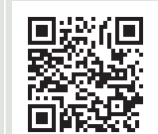 & $\begin{array}{l}\text { Scan this QR } \\
\text { code with your } \\
\text { smart phone or } \\
\text { mobile device } \\
\text { to read online. }\end{array}$ \\
\hline
\end{tabular}

Oxpeckers reduce tick loads on ungulate hosts, but they are also known to feed on and exacerbate wounds. An understanding of the feeding behaviours and host preferences of these birds is important since they serve as agents of tick control on both domestic and wild ungulates. We conducted an observational study at two sites within the Kruger National Park in South Africa, exploring the feeding preferences of both Red-billed and Yellow-billed Oxpeckers. Oxpeckers' host preferences, body-location preferences on different hosts, prevalence of feeding and non-feeding behaviours, and frequency of tolerance versus rejection in different hosts were determined. It was found that Yellow-billed Oxpeckers had a smaller range of hosts - typically larger-sized ungulates - and that Red-billed Oxpeckers diversify to smallersized ungulate hosts when in competition with Yellow-billed Oxpeckers. Body-location preferences were generally consistent across sites and across host species. Tick feeding and other host-feeding behaviours (around the eyes, nose, mouth and ears, and anogenital areas) were fairly common. Only six incidents of wound feeding, from a total of 855 observations, were recorded. Tolerance by an ungulate host species was not related to Oxpeckers' host preferences, suggesting that other factors such as ungulate body size, tick species and tick stages on the host animal may play a significant role in the feeding preferences of Oxpeckers.

Conservation implications: It is important to study Oxpeckers' behavioural feeding preferences so as to better understand their ecology and present distribution, and to determine where they can be reintroduced in future. Reintroduction not only helps with the proliferation of Oxpeckers, but also benefits ungulate hosts through ectoparasite removal and the subsequent control of tick-borne diseases.

\section{Introduction}

Red-billed Oxpeckers, Buphagus erythrorhynchus, and Yellow-billed Oxpeckers, B. africanus, are known to take part in symbiotic relationships with African ungulates (Dean \& MacDonald 1981; Mundy 1983). Oxpeckers reduce ectoparasite loads on host species and in return gain a major food source (Mooring \& Mundy 1996). By removing ectoparasites, Oxpeckers reduce host exposure to tick-borne diseases and the negative effects from ticks such as tick toxicosis, metabolic disturbances, anaemia and tick worry (Zieger et al. 1998).

In the wild, Oxpeckers generally prefer to forage for ticks (and other ectoparasites) on large herbivorous mammals such as Cape Buffalo (Syncerus caffer), Giraffe (Giraffa camelopardalis), Hippopotamus (Hippopotamus amphibius), Kudu (Tragelaphus strepsiceros), White Rhinoceros (Ceratotherium simum) and Plains Zebra (Equus quagga burchelli) (see Attwell 1966; Grobler 1980; Hustler 1987; Koenig 1997; Mooring \& Mundy 1996; Stutterheim \& Stutterheim 1980). Impala (Aepyceros melampus) are the exception to this generalisation since they are considered to be relatively small ungulates, but appear to be highly preferred (e.g. Grobler 1980; Hart, Hart \& Mooring 1990; Stutterheim \& Stutterheim 1980).

Ticks, the birds main food source, are obtained by either pecking at the skin of the host or by sweeping the head along the host's body whilst opening and closing the bill, a technique called 'scissoring' (Attwell 1966; Koenig 1997). These feeding techniques allow Oxpeckers to remove almost all adult ticks from a host (Bezuidenhout \& Stutterheim 1980). Whilst ticks are the main food source for both Oxpecker species, the birds are also known to feed on wound tissue, flies, mucous, saliva, earwax and blood (Stutterheim 1981; Weeks 2000).

Tick feeding is generally regarded as beneficial to the ungulate host (Dean \& MacDonald 1981), whereas wound feeding can be detrimental as it prolongs the healing time of wounds and increases the chance of infection (McElligott et al. 2004; Weeks 1999). A host is more likely to tolerate an Oxpecker performing a beneficial behaviour, and reject the bird that is wound feeding. Accordingly, one would expect Oxpeckers to feed more on ticks than on wounds. 
In South Africa, both Oxpecker species suffered population and range reductions during the first half of the 20th century, due to the treatment of livestock with poisonous acaricides, the over-hunting of large ungulates, and the rinderpest epidemic of 1896-1897 (Mundy 1983; Stutterheim 1982; Stutterheim \& Brooke 1981). These factors significantly reduced the numbers of host species and ticks, which in turn caused a decline in Oxpecker numbers and distribution. The remaining fragmented populations were restricted to protected areas and national parks (Grobler 1980; Stutterheim \& Brooke 1981).

With the advent of new Oxpecker-compatible ingredients in acaricides, the reintroduction of Oxpeckers from national parks into areas within their historic range has been possible and remains a useful conservation tool for ensuring the long-term survival of this species in South Africa. As part of conserving these birds, it is important to study Oxpeckers' behavioural preferences in their present natural habitat so as to better understand where they can be reintroduced in future. Reintroduction not only helps with the proliferation of Oxpeckers, but also benefits ungulate hosts through ectoparasite removal and the subsequent control of tickborne diseases.

Research on the feeding ecology of Oxpeckers has been carried out in various areas in east and southern Africa. However, very few of these studies have actually explored interspecific feeding behaviours in sympatric cases (Hustler 1987; Koenig 1997; Plantan 2009). Yellow-billed Oxpeckers have thicker bills and significantly heavier bodies compared to the slender-built Red-billed Oxpeckers (Mundy 1983). In allopatric studies, both species appear to forage on similar host species (Grobler 1980; Grobler \& Charsley 1978; Mooring \& Mundy 1996). However, given their differences in bill size and body mass, one would expect some level of interspecific competition, where an overlap of range distribution might occur. Furthermore, previous results suggest that the relationship between Oxpeckers and ungulates is primarily mutualistic (see Nunn et al. 2011), but few studies have argued that the relationship may also be parasitic (McElligott et al. 2004; Plantan et al. 2013; Weeks 1999).

In this study, the feeding preferences of both Red-billed and Yellow-billed Oxpeckers at two different locations (north versus south) within the Kruger National Park (KNP) in South Africa were examined. The differences in feeding behaviour between the species and between sites were evaluated. Site differences were only considered for Red-billed Oxpeckers since they were found in both the north and south of KNP, whereas Yellow-billed Oxpeckers were only sighted in the northern regions of the park. Oxpeckers' host preferences, body-location preferences on hosts, tolerance by host species and prevalence of feeding behaviours were recorded.

\section{Materials and methods Study area}

This study was carried out between September 2013 and

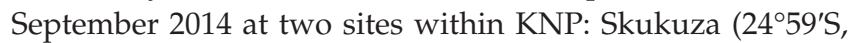

$\left.31^{\circ} 46^{\prime} \mathrm{E}\right)$ and Shingwedzi $\left(23^{\circ} 6^{\prime} \mathrm{S}, 31^{\circ} 25^{\prime} \mathrm{E}\right)$. The survey area for each site covered a radius of approximately $50 \mathrm{~km}$ from each of these rest camps and data collection was done biannually (September 2013, February 2014 and September 2014).

Skukuza is located in the southern section of KNP. The area sits on granitic rock and consists of slightly undulating plains. Broad-leaved bushveld is found in the uplands and fine-leaved bushveld in the bottomlands. Skukuza receives $500 \mathrm{~mm}-750 \mathrm{~mm}$ of rainfall per year. Shingwedzi is located in the northern regions of KNP and consists of flat plains of broad-leaved shrubveld that are dominated by mopane (Colophospermum mopane) woodlands. It receives $450 \mathrm{~mm}$ - $500 \mathrm{~mm}$ of rainfall per year and sits on basaltic rock (Venter, Scholes \& Eckhardt 2003). Red-billed Oxpeckers occur throughout KNP, whilst Yellow-billed Oxpeckers are abundant in the north of the park (Chittenden \& Whyte 2007).

\section{Fieldwork}

Data were collected early in the morning (07:00-10:00) and late in the afternoon (15:00-18:00), which coincides with Oxpeckers' peak feeding periods (Plantan 2009). Three game drive vehicles were used during each sampling period. Each vehicle drove along non-overlapping routes at each study site area, looking for potential host species with or without Oxpeckers. Each vehicle carried between six and eight occupants. Field observations were conducted using binoculars, and only Oxpeckers observed within $200 \mathrm{~m}$ of the vehicle were included. Observers in each vehicle recorded data using CyberTracker software, accessed using Smartphones. CyberTracker enables the researcher to rapidly enter data electronically whilst still in the field.

The observation techniques used were similar to that of Grobler (1980), Stutterheim and Stutterheim (1980) and Plantan (2009). Each time a host species was encountered, data were collected on the following: (1) identity of the host species, (2) number of hosts available, (3) number of Oxpeckers present, (4) Oxpecker species, (5) age class of each Oxpecker observed, (6) presence or absence of wounds on host, (7) location of Oxpecker on host, (8) behaviour of each Oxpecker, (9) host response (tolerance or rejection) and (10) GPS coordinates and time of each observation.

Behaviours were divided into wound feeding behaviours, non-wound feeding behaviours (tick-, anogenital-, ear-, nose-, eye- and mouth feeding) and non-feeding behaviours (perching or preening). Behavioural observations of birds were done within a 2 min period or until the bird was no longer visible or flew off the host.

When estimating host numbers in instances where large numbers of animals were present and an accurate count was not possible, a probable underestimate of the total number was made. A host was considered to have a wound if the skin had a visible break, whether or not blood was present. Oxpecker behaviour was considered to be rejected if the 
host animal actively tried to dislodge the bird through legstomping, nose-pushing, head-shaking, actively running away, etc.

\section{Data analysis}

To determine Oxpeckers' host preferences, the method of Stutterheim and Stutterheim (1980) was used to obtain a preference index (PI) for each host species (number of birds or number of animals). Chi-square tests were then used to compare preference index distributions between sites and between species. A similar analysis was also conducted to compare the results of the present study to historic data sets from Stutterheim and Stutterheim (1980) and Grobler (1980).

Simple arithmetic was used to determine Oxpeckers' hostbody-location preferences and the prevalence of different bird behaviours (i.e. non-feeding, tick feeding, wound feeding or other feeding) was also compared. The frequency of the hosts' response to various Oxpeckers' behaviours (tolerance or rejection) was also explored. A linear regression model in RStudio (2013) was used to determine whether tolerance by a host species was related to the host preferences of Oxpeckers.

\section{Results}

In Skukuza, 6107 potential host animals and 329 Red-billed Oxpeckers were observed, with 511 behavioural instances recorded. In Shingwedzi, 2254 potential hosts and 158 Oxpeckers were observed, with 344 behavioural instances recorded. Of the Oxpeckers in Shingwedzi, 120 were Redbilled Oxpeckers and only 38 were Yellow-billed Oxpeckers.

Overall, the most preferred host species for Oxpeckers in KNP was White Rhinoceros (PI = 0.60) and Giraffe $(P I=0.54)$. Kudu and Cape Buffalo were also highly preferred, with PIs of 0.18 and 0.17 , respectively. Oxpeckers were also present on Hippopotamus, Plains Zebra and Impala (Figure 1). Impala, whilst not highly preferred, were still important hosts due to their high abundance. More than $25 \%$ of all observed Oxpeckers were found on Impala, which also made up $74 \%$ of all observed host species. Red-billed Oxpeckers had different host animal preferences in Skukuza compared to Shingwedzi (Figure 2). White Rhinoceros, an important host animal in Skukuza, was not recorded in Shingwedzi. Plains Zebra was observed in both locations, but was only utilised as a host in Shingwedzi. Of the five host animals utilised in both areas, Red-billed Oxpeckers in Shingwedzi showed a higher preference for Kudu, Hippopotamus and Impala, compared to Skukuza birds $\left(\mathrm{X}_{(4)}^{2}=251.20, p<0.001\right)$. Yellowbilled Oxpeckers had a smaller range of host animals than their Red-billed counterparts $\left(\mathrm{X}_{(5)}^{2}=30.59, p<0.001\right)$. Yellowbilled Oxpeckers were only found on Giraffe, Cape Buffalo and Plains Zebra, whilst Red-billed Oxpeckers in the same area were also found on Kudu, Hippopotamus and Impala (Figure 3).

A comparison of the present preference indices to those of Grobler (1980) and Stutterheim and Stutterheim (1980) revealed differences in host preferences (Table 1). Oxpeckers in Skukuza preferred White Rhinoceros and, in contrast, was not a significant host animal in earlier studies. Hippopotamus was not recorded as a host in the 1980 studies, but was a minor host in the findings of the present study. Cape Buffalo

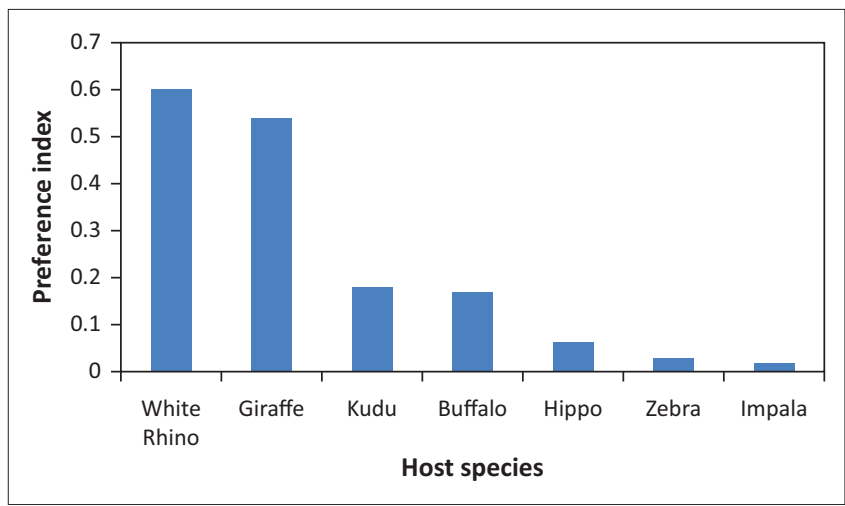

FIGURE 1: Host preferences of Red-billed and Yellow-billed Oxpeckers from both Skukuza and Shingwedzi areas in the Kruger National Park. Preference index is a ratio of the number of birds seen on a given host species divided by the number of hosts seen of that species.

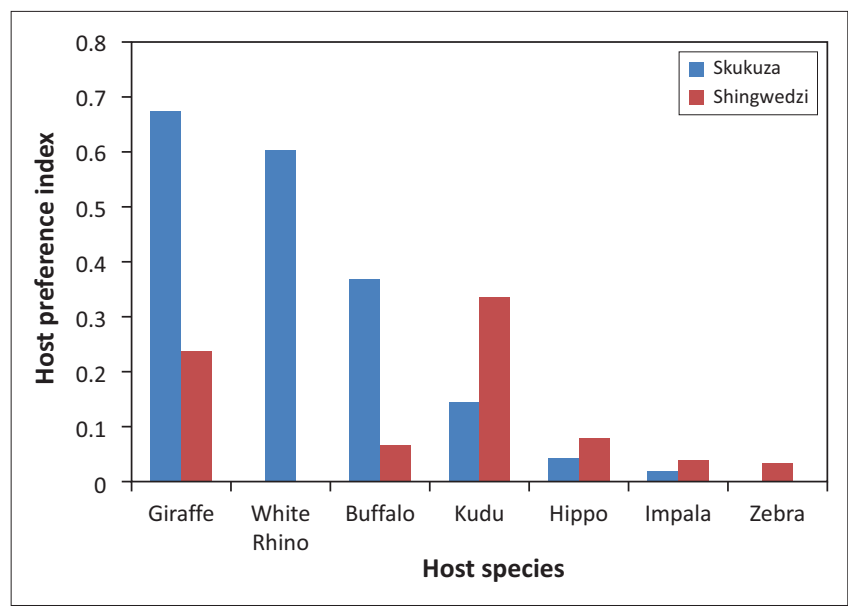

FIGURE 2: A comparison of host preference indices for Red-billed Oxpeckers in the Skukuza and Shingwedzi areas of the Kruger National Park.

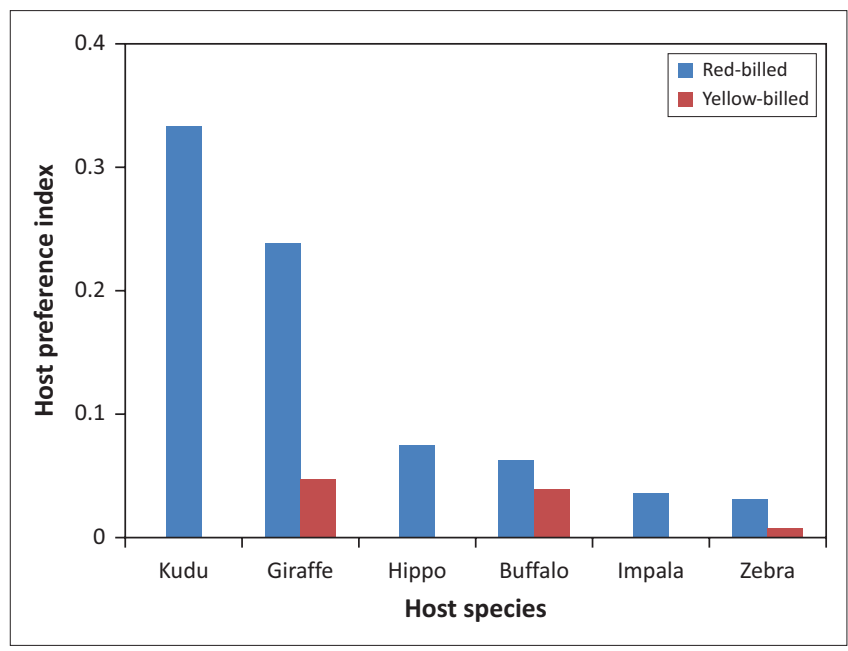

FIGURE 3: A comparison of host preference indices for Red-billed and Yellowbilled Oxpeckers in the Shingwedzi area of the Kruger National Park. 
in Skukuza was the preferred host, contrary to earlier findings from previous studies (Grobler 1980) in the same region $\left(\mathrm{X}_{(3)}^{2}=148.32, p<0.001\right)$. Compared to Stutterheim and Stutterheim (1980), data from Shingwedzi (present study) indicate less preference for Cape Buffalo and Giraffe, and more preference for Impala, Kudu and Plains Zebra $\left(\mathrm{X}^{2}{ }_{(4)}\right.$ $=83.26, p<0.001$ ).

A total of 419 body-location preference instances were recorded. Red-billed Oxpeckers were most frequently observed on the back $(41 \%, n=170)$, head $(20 \%, n=83)$ and neck $(16 \%, n=65)$. The neck was particularly preferred on Giraffe $(40 \%, n=25)$, whilst the flanks were also important for Kudu (19\%, $n=7)$. Oxpeckers were also seen on the legs and anogenital regions of hosts (Figure 4).

A total of 386 unique behavioural incidences were recorded for Red-billed Oxpeckers at both sites. The most frequently recorded behaviour was non-feeding $(44 \%, n=169)$, but tick feeding $(38 \%, n=145)$ and other forms of host feeding $(17 \%, n=66)$ were also prevalent (Figure 5). Only $1.6 \%$ of all behavioural observations were of wound feeding $(n=6$; Redbilled Oxpecker $=6$, Yellow-billed Oxpecker $=0$ ). Yellow-

TABLE 1: Host preference indices from this study, compared to previous studies in the Kruger National Park.

\begin{tabular}{lccccc}
\hline Host species & \multicolumn{2}{c}{ Southern KNP } & & \multicolumn{2}{c}{ Northern KNP } \\
\cline { 2 - 3 } \cline { 5 - 6 } & $\begin{array}{c}\text { Grobler } \\
\mathbf{( 1 9 8 0 )}\end{array}$ & $\begin{array}{c}\text { Present } \\
\text { study }\end{array}$ & & $\begin{array}{c}\text { Stutterheim and } \\
\text { Stutterheim (1980) }\end{array}$ & $\begin{array}{c}\text { Present } \\
\text { study }\end{array}$ \\
\hline White Rhinoceros & 0.00 & 0.60 & & - & - \\
Giraffe & 1.10 & 0.67 & & 0.67 & 0.29 \\
Cape Buffalo & 0.11 & 0.37 & & 0.20 & 0.10 \\
Kudu & 0.13 & 0.14 & & 0.28 & 0.33 \\
Hippopotamus & 0.00 & 0.04 & & - & 0.08 \\
Plains Zebra & 0.00 & 0.00 & & 0.02 & 0.04 \\
Impala & 0.02 & 0.02 & & 0.02 & 0.04 \\
\hline
\end{tabular}

Source: Grobler, J.H., 1980, 'Host selection and species preference of the Red-billed Oxpecker Buphagus erythrorhynchus in the Kruger National Park', Koedoe 23, 89-97. http://dx.doi. org/10.4102/koedoe.v23i1.637 and Stutterheim, C.J. \& Stutterheim, M., 1980, 'Evidence of an increase in a red-billed Oxpecker population in the Kruger National Park', South Africa an increase in a red-billed Oxpecker population in the Kruger National Park', South Journal of Zoology 15(4), 284. http://dx.doi.or
0.00 , hosts observed, but without Oxpeckers.

0.00 , hosts observed, but
KNP, Kruger National park.

- , no host animals observed.

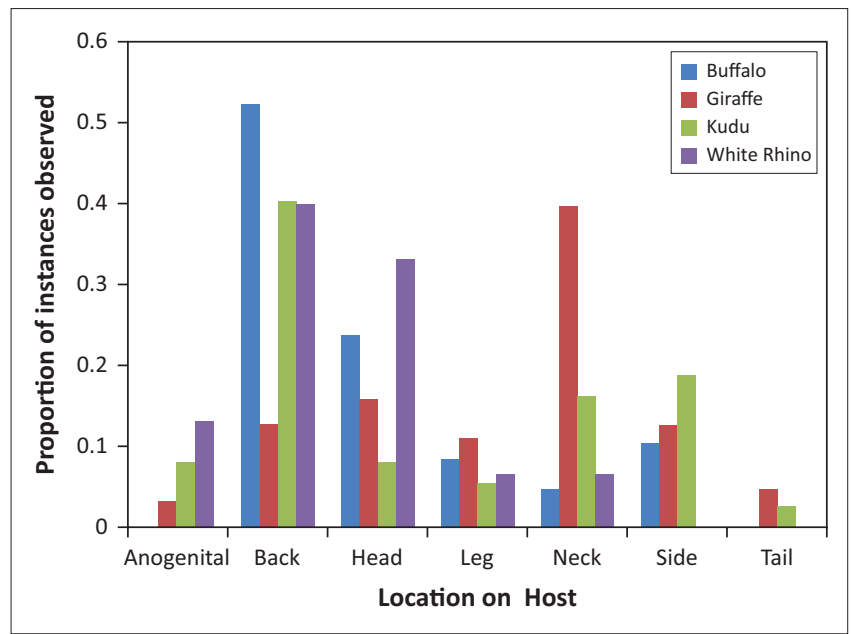

FIGURE 4: Body-location preferences on the preferred hosts of Red-billed Oxpeckers in the Skukuza and Shingwedzi areas. billed Oxpeckers were only seen feeding whilst on Cape Buffalo ( $n=17)$; all observations of Yellow-billed Oxpeckers on other hosts were of non-feeding birds.

A total of $80 \%$ of host animals observed throughout the study at both sites appeared to be tolerant of Oxpeckers (Table 2). The most tolerant host animals were Giraffe, White Rhinoceros and Hippopotamus. Cape Buffalo, Plains Zebra, Impala and Kudu were slightly less tolerant. There was a non-significant correlation between the degree of tolerance of a host species and Oxpeckers' preference for that same host $\left(r^{2}=0.486, F=4.723, p=0.082\right)$.

\section{Discussion}

The aim of the present study was to provide insight and understanding of both Red-billed and Yellow-billed Oxpeckers' feeding behaviours, particularly regarding host and body-location preferences. Overall, Red-billed and Yellow-billed Oxpeckers displayed a host preference for large ungulates (White Rhinoceros, Giraffe and Cape Buffalo). These findings are similar to previous studies (Attwell 1966; Grobler 1980; Hustler 1987; Stutterheim \& Stutterheim 1980). This preference could be a result of larger ungulates providing a greater surface area for ectoparasites, which are therefore able to carry larger tick loads (Horak et al. 1983; Koenig 1997; Mooring \& Mundy 1996). Generally, large ungulates have many ectoparasites, particularly ticks at various life cycle stages (Grobler \& Charsley 1978; Mooring \& Mundy 1996). Large ungulates also have a limited ability to

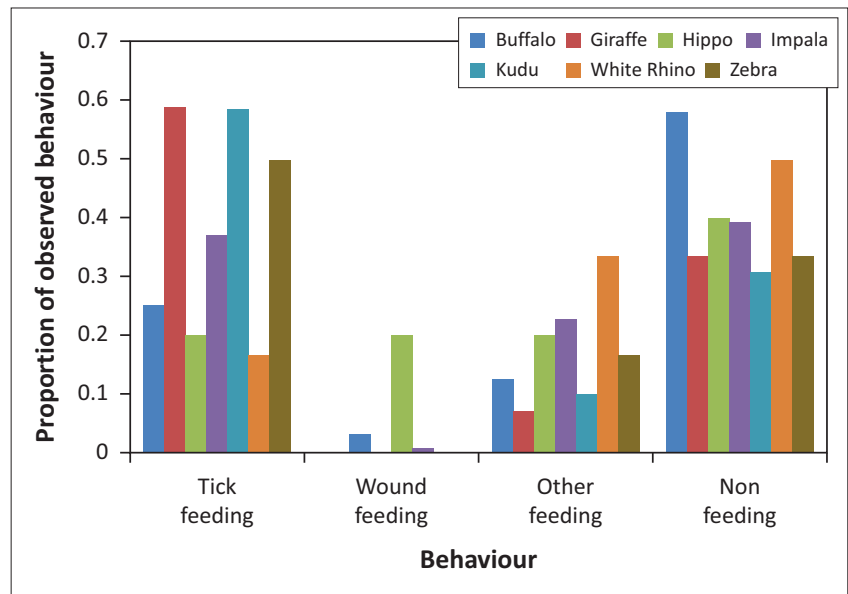

FIGURE 5: The frequency of Red-billed Oxpeckers' behaviours on different ungulate host species in the Skukuza and Shingwedzi areas.

TABLE 2: Tolerance and rejection instances by host species in the Skukuza and Shingwedzi areas.

\begin{tabular}{lcccc}
\hline Host species & Tolerant & Rejection & Total instances & Proportion tolerant \\
\hline Giraffe & 104 & 2 & 106 & 0.981 \\
White Rhinoceros & 18 & 1 & 19 & 0.947 \\
Hippopotamus & 13 & 1 & 14 & 0.929 \\
Cape Buffalo & 293 & 34 & 327 & 0.896 \\
Plains Zebra & 14 & 2 & 16 & 0.875 \\
Impala & 273 & 44 & 317 & 0.861 \\
Kudu & 46 & 10 & 56 & 0.821 \\
\hline
\end{tabular}


self-groom, which subsequently maintains, if not increases, their tick loads (Mooring \& Mundy 1996). Additionally, the three most preferred host species are often gregarious, travelling and feeding in large numbers, and therefore potentially increasing tick abundance, transmission and prevalence (Koenig 1997).

Differences in host preferences were observed between populations of Red-billed Oxpecker in the Shingwedzi and Skukuza regions, with the Shingwedzi population selecting for smaller ungulates (see Figure 2). Red-billed Oxpeckers appear to be limited to medium and small-sized ungulates, such as Kudu and Impala, in the northern parts of KNP. This is most likely because of a home range overlap with Yellowbilled Oxpeckers, resulting in interspecific competition (Koenig 1997). The larger (in terms of body size) Yellowbilled Oxpecker is territorial and capable of outcompeting the smaller Red-billed Oxpecker (Hall-Martin 1987), permitting the former a preferential choice of ungulates. The study also shows that Red-billed Oxpeckers in the southern regions of KNP utilised the preferred large ungulates in the absence of Yellow-billed Oxpeckers, whereas their preference shifted to smaller ungulates in the presence of Yellow-billed Oxpeckers. This further supports the notion of interspecific competition between Red-billed and Yellow-billed Oxpeckers for access to larger ungulate hosts.

Contrary to the results from the present study, Hustler (1987) and Koenig (1997) in Zimbabwe and Kenya (respectively) did not find any differences in host ungulate preferences when both species occurred within the same geographic region. Furthermore, Koenig (1997) did not find any marked differences in the host species preferences of Red-billed Oxpeckers when comparing between areas of sympatry and areas of allopatry. Perhaps these differences between the Kenya study and the KNP findings could be attributed to differences in ungulate densities between the two sites. One would assume that the Kenya sites (Masai Mara Reserve and Lake Nakuru National Park) had a high abundance of large ungulates compared to KNP, hence a marked host preference would only be apparent in lower ungulate densities where interspecific competition is unavoidable. However, that hypothesis cannot be tested without a measure of ungulate densities from all sites.

Surprisingly, the PI results in the present study differed from Grobler (1980) and Stutterheim and Stutterheim (1980). The most plausible explanation is that these differences are related to changes in large ungulate numbers and distribution within KNP in the past 30 years (Chirima, Owen-Smith \& Erasmus 2012; SANParks 2012), coupled with a possible switch in Oxpeckers' host preferences in response to changing ungulate densities. Optimal foraging strategy (Pyke 1984) will predict that animals will concentrate on the most abundant and profitable food source. For example, there were fewer White Rhinoceros and Hippopotamus in KNP in the 1980s compared to the present-day population (2014). It is therefore reasonable to conclude that as White Rhinoceros and Hippopotamus numbers increased, Red-billed Oxpeckers responded by selecting for these new abundant host species with potentially higher tick loads and less hair to hide the ticks.

Giraffe remained the most preferred host species in both the northern and southern regions of the park. This could also be a detection bias, given that it is possibly easier for flying birds to detect Giraffe compared to other (shorter) species. Nevertheless, it is reasonable to conclude that size plays a major role in Oxpeckers' host preferences (Grobler 1980; Grobler \& Charsley 1978; Koenig 1997; Mooring \& Mundy 1996; Stutterheim 1982; Stutterheim \& Brooke 1981). This is further supported by Oxpeckers' preference for White Rhinoceros and Hippopotamus (both large ungulates), recorded as host species in Skukuza. Interestingly, Impala, an abundant, small-sized ungulate, was less preferred as a host species across studies. This surprising contradicts what has been reported by Grobler (1980), Stutterheim and Stutterheim (1980) and Hart et al. (1990).

Both Red-billed and Yellow-billed Oxpeckers displayed a preference for the back and head regions of their respective host species. Red-billed Oxpeckers also preferred the necks of Giraffe. These preferences coincide with body regions that are likely to exhibit higher tick abundance, given the degree of difficulty in tick-grooming access (Mooring \& Mundy 1996; Weeks 1999) and are often the areas that exhibit more wounds (pers. obs.). Additionally, Oxpeckers prefer feeding on the back regions of a host species since this is easily accessible and provides a stable perch (Weeks 1999). The low prevalence of tick feeding by both Oxpecker species on body regions that are easily self-groomed by the host species, such as the legs, further supports the possibility that Oxpeckers show a preference for non-groomed body regions for their higher tick loads (Koenig 1997; Mooring \& Mundy 1996). The head is also preferred since it provides additional food resources other than ticks, i.e. saliva, mucus and earwax (Stutterheim 1981).

Exceedingly low occurrences of wound feeding by Red-billed Oxpeckers and the absence of wound feeding in Yellowbilled Oxpeckers suggests that this feeding behaviour is not prevalent in KNP as previously reported in cattle ranches in Zimbabwe (Weeks 2000). Plantan (2009), in her study on both Oxpecker species at Shingwedzi in 2007, also found the prevalence of wound feeding behaviour to be very low $(3.1 \%$ of 558 feeding observations). However, she did find that wound feeding was exhibited by Yellow-billed Oxpeckers more than Red-billed Oxpeckers. In the current study, there were instances where ungulates were observed with open wounds and yet Oxpeckers did not tamper with the wounds, but rather continued tick feeding. This observation further suggests that Oxpeckers pose no risk to free-roaming wildlife.

Large ungulates tolerated Oxpeckers more so than medium-sized ungulates. This tolerance is inadvertently due to the reduced agility of large ungulates, providing a more stable perch and a greater feeding area (Grobler 1980; Hustler 1987; Stutterheim \& Stutterheim 1980; 
Weeks 1999). The preferential selection of larger hosts also indicates that reintroductions of Oxpeckers should target areas with high tick loads and substantial, large ungulate populations of the host species that are preferred. However, conservationists should also consider that Oxpeckers prefer certain tick species and tick stages (Mooring \& Mundy 1996). Therefore, even if a large ungulate has many ticks, this does not mean that the Oxpecker will consume those ticks or utilise the host. However, the present study does provide additional insight and understanding of Redbilled and Yellow-billed Oxpeckers' feeding behaviours, particularly in KNP and in terms of wild host species and body-location preferences.

\section{Acknowledgements}

The authors would like to thank the SANParks Scientific Services at KNP, staff and students at the Organization for Tropical Studies (OTS) and the Endangered Wildlife Trust for their support in this project. SANParks issued permits for this research project to OTS South Africa.

\section{Competing interests}

The authors declare that they have no financial or personal relationship(s) that may have inappropriately influenced them in writing this article.

\section{Authors' contributions}

M.N. (University of the Witwatersrand) and L.C. (The Endangered Wildlife Trust) were both responsible for the project design, data collection and management of the study. M.N. performed most of the data analysis and wrote the first draft of the article. L.C. made conceptual contributions to the article, did the literature review and revised the drafts.

\section{References}

Attwell, R.I.G., 1966, 'Oxpeckers and their associations with mammals in Zambia', Puku 4, 17-48.

Bezuidenhout, J.D. \& Stutterheim, C.J., 1980, 'A critical evaluation of the role played by the red-billed Oxpecker Buphagus erythrorhynchus in the biological control of ticks', Onderstepoort Journal of Veterinary Research 55, 173-179.

Chirima, G.J., Owen-Smith, N. \& Erasmus, B.F.N., 2012, 'Changing distributions of larger ungulates in the Kruger National Park from ecological aerial survey data', Koedoe 54(1), Art.\#1009, 11 pages. http://dx.doi.org/10.4102/koedoe.v54i1.1009

Chittenden, H. \& Whyte, I., 2007, Roberts bird guide: Kruger National Park and Adjacent Lowveld, John Voelcker Bird Book Fund, Cape Town.

Dean, W.R.J. \& MacDonald, I.A.W., 1981, 'A review of African birds feeding in association with mammals', Ostrich 52, 135-155. http://dx.doi.org/10.1080/003 06525.1981.9633599
Grobler, J.H., 1980, 'Host selection and species preference of the Red-billed Oxpecker Buphagus erythrorhynchus in the Kruger National Park', Koedoe 23, 89-97. http:// Buphagus erythrorhynchus in the Kruge
dx.doi.org/10.4102/koedoe.v23i1.637

Grobler, J.H. \& Charsley, G.W., 1978, 'Host preference of the yellow-billed Oxpecker in the Rhodes Matopos National Park, Rhodesia', South African Journal of Wildlife Research 8, 169-170.

Hall-Martin, A.J., 1987, 'Range expansion of the Yellowbilled Oxpecker Buphagus africanus into the Kruger National Park, South Africa', Koedoe 30, 121-132. http:// dx.doi.org/10.4102/koedoe.v30i1.505

Hart, B.L., Hart, L.A. \& Mooring, M.S., 1990, 'Differential foraging of Oxpeckers on impala in comparison with sympatric antelope species', African Journal of Ecology 28, 240-249. http://dx.doi.org/10.1111/j.1365-2028.1990.tb01157.x

Horak, I.G., Potgieter, F.T., Walker, J.B., De Vos, V. \& Boomker, J., 1983, 'The ixodid tick burdens of various large ruminant species in South African nature reserves', Onderstepoort Journal of Veterinary Research 50, 221-228. PMID: 6646664.

Hustler, K., 1987, 'Host preference of Oxpeckers in the Hwange National Park Zimbabwe', African Journal of Ecology 25(4), 241-245. http://dx.doi. org/10.1111/j.1365-2028.1987.tb01115.x

Koenig, W.D., 1997, 'Host preferences and behaviour of Oxpeckers: Co-existence of similar species in a fragmented landscape', Evolutionary Ecology 11, 91-104. http://dx.doi.org/10.1023/A:1018439614008

McElligott, A.G., Maggini, I., Hunziker, L. \& König, B., 2004, 'Interactions between redbilled Oxpeckers and black rhinos in captivity', Zoo Biology 23(4), 347-354. http:// dx.doi.org/10.1002/zoo.20013

Mooring, M.S. \& Mundy, P.J., 1996, 'Interactions between impala and Oxpeckers at Matobo National Park, Zimbabwe', African Journal of Ecology 34, 54-65. http:// dx.doi.org/10.1111/j.1365-2028.1996.tb00594.x

Mundy, P.J., 1983, 'The Oxpeckers of Africa', African Wildlife 37, 111-116.

Nunn, C.L., Ezenwa, V.O., Arnold, C. \& Koenig, W.D., 2011, 'Mutualism or parasitism? Using a phylogenetic approach to characterize the Oxpecker-ungulate relationship', Evolution 65(5), 1297-1304. PMID: 21166791, http://dx.doi.org/10.1111/j.15585646.2010.01212.x

Plantan, T.B., 2009, 'Feeding behavior of wild and captive Oxpeckers (Buphagus spp.): A case of conditional mutualism', PhD thesis, University of Miami, Florida.

Plantan, T.B., Howitt, M., Kotze, A. \& Gaines, M.S., 2013, 'Feeding preferences of the red-billed Oxpecker, Buphagus erythrorhynchus: A parasitic mutualist?', African Journal of Ecology 51, 325-336. http://dx.doi.org/10.1111/aje.12042

Pyke, G.H., 1984, 'Optimal foraging theory: A critical review', Annual Review of Ecology and Systematics 15, 523-575. http://dx.doi.org/10.1146/annurev. es.15.110184.002515

RStudio, version 0.98.1028, 2013, computer software, RStudio, Inc., Boston, MA.

SANParks, 2012, 'Estimates for animal abundances in parks in the northern region', South African National Parks Annual Report 2011/2012, viewed 03 November 2014, from http://www.sanparks.co.za/assets/docs/general/annual-report-2012.pdf

Stutterheim, C.J., 1981, 'The feeding behaviour of the redbilled Oxpecker', South African Journal of Zoology 16(4), 267-271.

Stutterheim, C.J., 1982, 'Past and present ecological distribution of the redbilled Oxpecker (Buphagus erythrorhynchus) in South Africa', South African Journal of Zoology 17(4), 190-196. http://dx.doi.org/10.1080/02541858.1982.11447802

Stutterheim, C.J. \& Brooke, R.K., 1981, 'Past and present ecological distribution of the yellowbilled Oxpecker in South Africa', South African Journal of Zoology 16(1), 44-49.

Stutterheim, C.J. \& Stutterheim, M., 1980, 'Evidence of an increase in a red-billed Oxpecker population in the Kruger National Park', South Africa Journal of Zoolog 15(4), 284. http://dx.doi.org/10.1080/02541858.1980.11447724

Venter, F.J., Scholes, R.J. \& Eckhardt, H.C., 2003, 'The abiotic template and its associated vegetation pattern', in J.T. du Toit, K.H. Rogers \& H.C. Biggs (eds.), The Kruger experience: Ecology and management of savanna heterogeneity, pp. 83129 , Island Press, Washington, DC.

Weeks, P., 1999, 'Interactions between red-billed Oxpeckers, Buphagus erythrorhynchus, and domestic cattle, Bos taurus, in Zimbabwe', Animal Behavior 58(6), 1253-1259. PMID: 10600147, http://dx.doi.org/10.1006/anbe.1999.1265

Weeks, P., 2000, 'Red-billed Oxpeckers: vampires or tickbirds?', Behavioral Ecology 11(2), 154-160. http://dx.doi.org/10.1093/beheco/11.2.154

Zieger, U., Horak, I.G., Cauldwell, A.E., Uys, A.C. \& Bothma, J. du P., 1998, 'The effect of chemical tick control on cattle on free-living ixodid ticks and on ticks parasitic on sympatric impala in the Central Province, Zambia', South African Journal of Wildlife Research 28(1), 10-15. 